\title{
EXPLORING THE IMPACT OF A SWISS BILINGUAL PROGRAM THROUGH A MIXED METHOD DESIGN
}

\author{
Emile Jenny ${ }^{1}$, \& Francesco Arcidiacono ${ }^{2}$ \\ ${ }^{1}$ Continuing Education, University of Teacher Education BEJUNE (Switzerland) \\ ${ }^{2}$ Research Department, University of Teacher Education BEJUNE (Switzerland)
}

\begin{abstract}
The use of mixed methods has increased in research over the past decades, especially in the field of education. In this article, we describe how the use of two methodological approaches led researchers to evaluate the competences of 10- to 12-year-old pupils in a bilingual public primary school in Switzerland. The following target disciplines have been selected for the aim of the study: L2 (French or German) and mathematics. The first part of the article focuses on quantitative aspects: by using close-ended questionnaires, L2-tests in four communicative competences and mathematics tests, we have compared the results of children following the bilingual program $(n=76)$ with the results of children following monolingual education $(n=214)$. The second part of the article describes the qualitative approach adopted in order to gain a better understanding of classroom activities and perceptions of a teacher involved in the bilingual program. This part includes the discursive analysis of classroom social interactions and the semi-structured interviews with teachers. The use of mixed methods has been helpful in detecting the complex context of knowledge production in the analyzed setting, in which the use of two languages has been effective in enhancing content and language learning. Therefore, recommendations for the growing number of bilingual programs such as benefits of combining methodological approaches are presented in the final part of the article.
\end{abstract}

Keywords: Mixed methods, communicative competences, mathematic skills, bilingual education.

\section{Introduction}

Considerable quantitative research has documented the modern bilingual education since its beginning in the 1960's, mostly in Canada. After two decades of exploring these programs, large reviews were published in the 1990's and showed that students from bilingual schools tend to develop strong L1- and L2-proficency (e.g., Calvé, 1991) and also tend to be more creative and flexible (Cathomas \& Carigiet, 2008). Qualitative research in this field started later and described different pedagogical aspects of the bilingual education, such as the type of interactions that take place within the lessons (e.g., Gajo, 2001) or the use of plurilingual competences (Moore, 2006) by the pupils. However, there is very little use of mixed methods aiming to get a global view on bilingual education.

This study aims to describe the competences of 10- to 12-year-old pupils in a specific type of bilingual program (two-way immersion) and to understand their development with two different approaches. First, we measured the competences in L2 and mathematics using standardized tests and questionnaires. Second, we attended one mathematics lesson and interviewed the teacher in order to explore the use of code-switching, the balance between content and language as well as the perceptions of this teacher.

In this article, we will first present a literature review on bilingual education. Then we will describe the methodological frame and the results of the study. Finally, we will give recommendations for the growing number of bilingual programs and emphasize the benefits of combining methodological approaches in the final part of the article.

\section{Literature review}

Bilingual Education has been studied from a number of angles since its beginning in the 1960's and different trends reflect the progress in research (Gajo, 2001). The first important studies on bilingual education were conducted in Canada and were focusing on the outputs and the cognitive competences of bilingual pupils. Some of them were skeptical about the idea of mixing languages and were arguing that learning one language could hinder the development of another (e.g. Penfield, 1965). The methods used by some researchers at that time were criticised as they consisted of comparing groups of local students as monolingual with immigrants as bilingual individuals. Nonetheless, the latter often had lower 
socio-economic status. Then qualitative research designs appeared in research on bilingual education and the focus was still set on the L2-Proficency. Calvé (1991) showed for example that the receptive competences (oral and written comprehension) of children from immersion programs were usually more developed than their productive competences (oral and written production). Lyster (1990) found out that the pupils of bilingual programs used to learn the L2 until a certain point but noticed that some mistakes were hard to erase. He called this phenomena "fossilization" and proposed the organization of L2-specific lessons in order to manage this issue. Nowadays research field on bilingual education has become wider and methodology has evolved. Gajo (2001) studied for example teacher-pupil interactions showing that the speaker tends to focus not only on the form but also on the content when addressing a public from another language. Berthoud and Gajo (2005) studied the balance between language structure and content in bilingual education. They concluded that learning a subject in more than one language could even be an advantage for the discipline as the students will need to reformulate what they heard, to reflect and to use the new contents in different contexts. Moore (2006) mentioned several studies showing that code-switching produced by bilingual children can have different functions such as using a more accurate word for which the speaker does not find an equivalence in the other language, putting distance from the concepts or building the language competence. These works showed the important role of school disciplines in bilingual education and, if those aspects are taken into account, the potential of bilingual education not only for the language but also for the subjects.

The lack of research on language and school disciplines in bilingual education using mixed method led us to conduct a study aiming to measure as a first step the competences in L2 and mathematics and, as a second step, to better understand the practices and perceptions of a teacher involved in the teaching of mathematics in German to a mixed group of French- and German-speaking students.

\section{Methods}

Mixed methods have been used in the fields of sociology and education over the past decades but there is little research on their use in bilingual education. Creswell (1999:9) defined mixed methods as methodologies "for conducting research that involves collecting, analyzing, and integrating quantitative and qualitative research in a single study or a longitudinal program of inquiry". They should be used when a more complete understanding of a phenomenon cannot be provided by either a quantitative or a qualitative approach alone.

As bilingual education and specifically two-way immersion requires more quantitative assessments in every new context but also qualitative approaches in order to understand their implication, we decided to describe and evaluate the competences of 10- to 12-year-old pupils in a bilingual public primary school in Switzerland using a mixed method. This school called "FiBi" introduced the idea of setting up classes with $50 \%$ of pupils with German as main language and 50\% of pupils with French as a main language starting at nursery level (children of 5 years old). This is only possible because the city, in which this study was conducted, has a balanced proportion of speakers of both languages. In this project, school disciplines are taught half in French and half in German using the model of "one person-one language" (1P/1L) described by Ronjat (1913). Today the FiBi-project has more than 300 pupils aged 5 to 12 years old.

The first part of the study measured the competences in L2 and in mathematics of children following a bilingual program $(n=76)$ and of a control group $(n=214)$, following monolingual education. The L2-tests were aiming to evaluate the four communicative competences described in Council of Europe (2001). They were adopted from Lenz and Studer (2014) and partly translated and adapted for the aim of this study. The mathematics tests were based on regional official curriculum goals. The exercises were inspired by standardized activities from Humbolt-University (2013) and completed by tests from local textbooks. Using closed-ended questionnaires, data on the linguistic and sociological profile of each student were collected. Then we compared the means of both groups by using Student $t$-Tests in SPSS.

In order to gain more of an overview on the classroom activities of this two-way immersion project and to question the findings presented above, we video-recorded mathematics lessons and we discussed with the teacher shortly afterwards by using a semi-structured detailed interview. Two cameras were used in order to cover a large part of the classroom and to benefit from two opposite angles. We briefly informed the pupils about the reason for our presence and asked them to behave as if we were not there. Of course the presence of both cameras and the researchers might have influenced the behaviour of the pupils, but we tried to minimise those effects. The class visit was examined through the analysis of social interactions, using the paradigm of discourse analysis.

\section{Findings}

The quantitative and qualitative data have been analysed separately and will therefore be presented in two different sections. In the discussion of the results the two parts will be linked and the relations between them will allow the formulation of interpretative hypotheses. 


\subsection{L2- and mathematical competences}

The scores of both groups in mathematics as well as in the four communicative competences (written comprehension, oral comprehension, oral expression and written expression) were compared with Student $t$-Tests. The results of this part are presented in Table 1.

Table 1. Comparison of means (Student $t$-Test) of both groups (FiBi and regular classes) in the tests of mathematics and $L 2$.

\begin{tabular}{|l|l|r|r|r|r|r|}
\hline & Group & $\mathrm{N}$ & \multicolumn{1}{c|}{ Mean } & Diff./max points. & Std & Sig. \\
\hline \multirow{2}{*}{ Mathematics } & Regul. & 214 & 25.84 & $4.27 / 54(7.91 \%)$ & 8.94 & .000 \\
& FiBi & 76 & 30.11 & & 8.73 & \\
\hline Written & Regul. & 208 & 2.89 & $.64 / 7(9.14 \%)$ & 1.03 & .000 \\
comprehension & FiBi & 76 & 3.53 & & 1.16 & \\
\hline Oral & Regul. & 208 & 2.89 & $.64 / 7(9.14 \%)$ & 1.24 & .001 \\
comprehension & FiBi & 76 & 3.53 & & 1.40 & \\
\hline Written & Regul. & 208 & 2.24 & $2.14 / 7(30.57 \%)$ & 1.21 & .000 \\
expression & FiBi & 76 & 4.38 & & 1.24 & .000 \\
\hline \multirow{2}{*}{ Oral expression } & Regul. & 200 & 2.79 & $3.30 / 7(47.14 \%)$ & 1.85 & .15 \\
& FiBi & 76 & 6.09 & & 1.15 & \\
\hline
\end{tabular}

The scores of FiBi students are significantly higher than the scores of non-FiBi students in the five situations. In mathematics the test has a total of 54 points and in L2 the total amount of points of each test was 7. In mathematics FiBi students have a mean of 30.11 points, which is 4.27 points $(7.91 \%)$ higher than the students of the regular classes. The difference is not as important as in the other tests but significant. Concerning the written competences, the result for comprehension competences is lower $(9.14 \%)$ than the result for productive competences $(30.57 \%)$. The difference is even larger concerning the oral competences with $9.14 \%$ for the comprehension and $47.14 \%$ for the expression. These aspects will be discussed in the next section of the paper. Generally speaking we observed a larger difference between both groups in the L2 than in the mathematics and, within the L2, an important difference between the competences concerning comprehension (reception) and expression (production).

\subsection{Class visit and semi-structured interview}

The observed mathematics lesson focused on quantities and proportions. The teacher first introduced a situation with all the students in front of the black board where he had drawn three orange juice bottles of different sizes linked to different prices. After a short discussion on elements influencing prices, the teacher sent the pupils back to their desks to do individual exercises. After a few minutes several pupils came back to the teacher in order to obtain specific explanations. During those explanations different interesting pupil-teacher interactions (with French-German code-switching) have been identified.

First the teacher sometimes translated the question into French directly after the question in German, like in the example below.

$$
16 \text { ROC was gibt acht mal fünfig rappen huit fois cinquante }
$$

This example shows a code-switching within the same sentence without any marks of change, probably in order to catch the attention of the French-speaking pupils. This way of changing the language in the middle of an output could also represent a way to stress an important part of the question that the teacher wants to make clear to the class.

The next example shows code-switching from a child during a phase where the teacher asks different students about the factors influencing the price of orange juice. One first student's answer is not audible but probably states that the profit should be a reason as the teacher repeats and validates this as one possible factor. Then a second student stresses that the time of the year may influence the price. The teacher validates this response but keeps asking for other factors. At this moment another student (EL06) says the answer "les transports" in French. The reaction of the teacher is interesting as he validates this answer by repeating the same word but in German and by rising his tone of voice. This example of code-switching shows at least two interesting aspects. On the one hand the interaction is not interrupted because all parts (students and teacher) are able to understand it and on the other hand the teacher stays focused on his question and the topic without starting an explanation about these words in both languages.

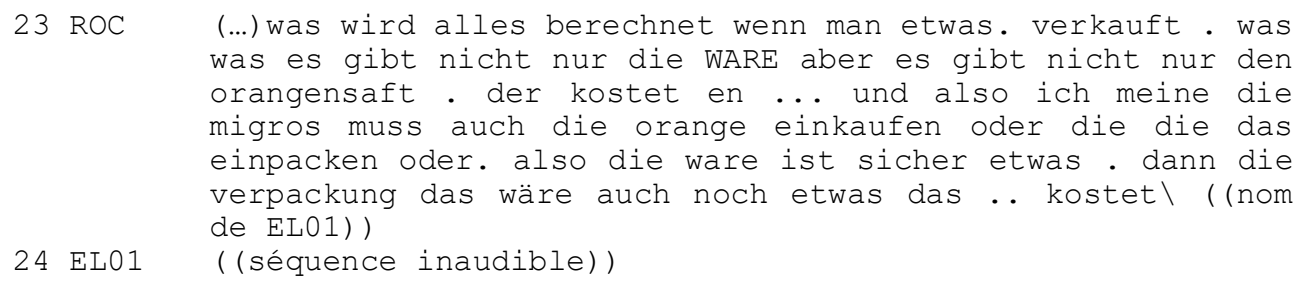




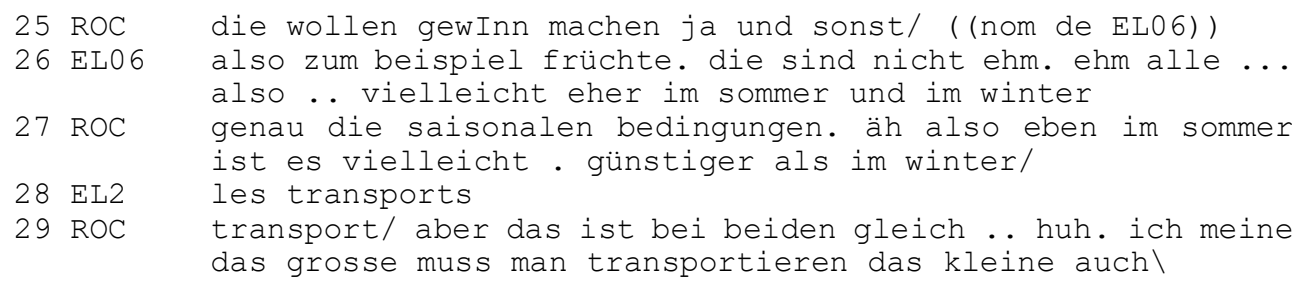

The most likely reason for the emergence of this code-switching is probably that the student does not know the word in German but wants to answer the question asked by the teacher anyway. This example shows the intention of the student of giving an accurate answer without making a linguistic issue and hence, keeping the focus on the content. We can hypothesise that this kind of code-switching benefits the disciplines and the language as the interaction about the price of orange juice move forward while the rest of the class hear one world (very similar in this case) in French and in German in a very short period of time. For the pupil that switched the language this could be a sort of decontextualization as the word he used in French is then introduced in turn by the teacher and hence, in the mathematics lessons.

The analysis of the interview with this teacher gives more information about the didactic organisation of the lessons and of the perceptions of the teacher about it. This article will not be able to show all the important aspects, but we present here the main findings regarding code-switching and the language-content balance. First the teacher explains that he has to adapt his way of teaching to the FiBi-population as he has French- and German-speaking students as well as speakers of many other languages attending his lessons. Indeed he argues that he uses more non-verbal communication such as gestures or illustrations than in monolingual programs. He also states that he uses code-switching usually as a last option when a child does not understand something, but he does not mention the potential of code-switching for the construction of linguistic competences. He stresses that the guideline of the project states that one teacher should speak only one language, referring to Ronjat's model. Hence he explains that he sometimes asks students to translate one word, but he never plans in advance such an intervention (or part of it) in French. This last aspect is exemplified in the following extract.

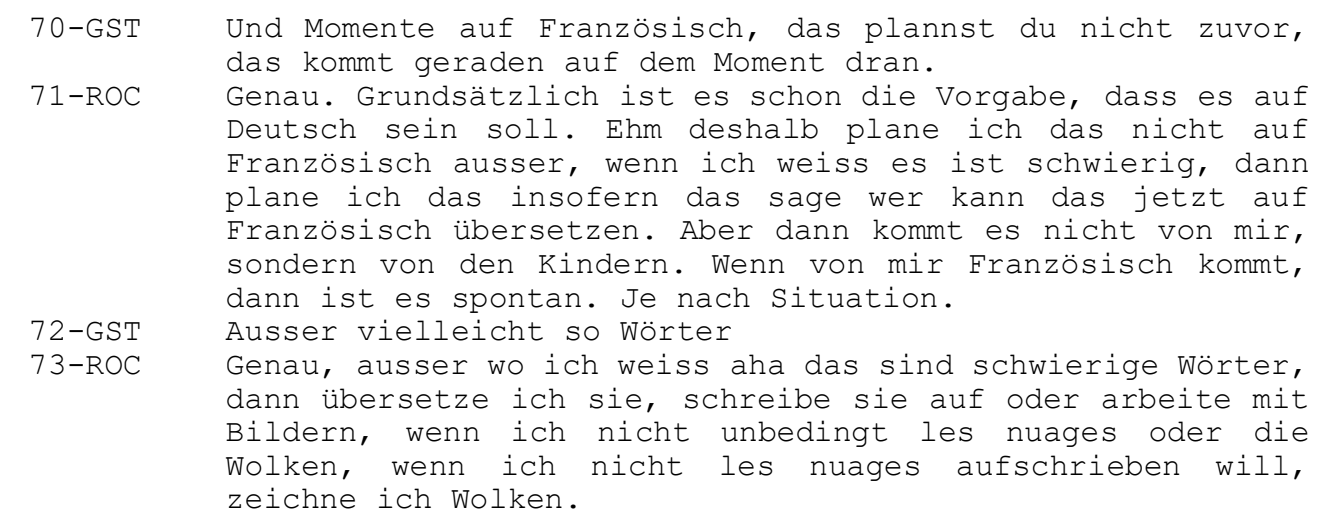

This example shows that the teacher uses French only in a spontaneous way and that he prefers to draw something rather than to use the translation. As mentioned above he does not plan the use of French in his classes, but he can do it if needed. In this case he would rather ask a pupil to translate, which is a possible way of making others participate in linguistics issues during the lesson.

The interviewee states that the writing productive competences represent one main issue of this project as he noted that French-speaking children tend to translate word by word from French into German. Finally, this teacher declares that he mostly focuses on the contents during the mathematics lessons but that he would immediately correct the form if one student would say something wrong. This is probably one other important aspect of two-way immersion that we will link to the results of the quantitative analyses in the next chapter.

\section{Discussion and conclusion}

Quantitative data showed that the FiBi-pupils developed significantly higher competences in L2 when compared to students of regular classes. This result is in line with the main findings from Canada presented by Calvé (1991). Nonetheless, we noticed larger differences in the productive rather than in the receptive competences, which could be seen as a potential benefit of the presence of speakers of L1 and L2 within the same class. Indeed, this mixed composition of the classes enables interactions on two levels: pupil to teacher and pupil to pupil. The second type of interaction is only possible in mixed classes and is surely improving the language productive competences of those pupils as they have more application opportunities. Another possible explanation for this difference is the construction of the tests in a communicative approach, which allow the pupils to make mistakes as long as the message is 
understandable. The studies from the 1990's were probably giving more weight to the exact accuracy on the outputs of the children.

The interview of the teacher shows that the interactions in L1 and in L2 are quite natural for children of his class. The quantitative findings regarding competences in mathematics can easily be related to the researches of Gajo (2001) and Gajo and Berthoud (2005) as the FiBi-population has better results than the students from regular classes. The use of two languages in pupil-pupil interactions could represent a way of putting distance from the concepts in a sort of decontextualization (Moore, 2006) and learn the content through multiple tools. Examination of class activities showed that the mathematics lessons were focusing on mathematical aspects and not on linguistic issues, which sometimes is presented as a confusion in bilingual education. Indeed, the interaction was not interrupted when a student would produce an output in French during the mathematics lesson in German, as shown in the example of the sequence of the transcript above.

Qualitative data show how the code-switching situation can serve a number of different purposes. First, it is sometimes used as an unplanned way to catch the attention of the pupils with a different language and this was confirmed in the interview. But it is also a way for pupils to be more accurate (as in the example of the sequence about the price of orange juice) with the possibility to use the exact word. Interesting is that this aspect did not slow down the lesson in the example presented above. This aspect can be related to the general findings of the quantitative part of this study. Indeed, if the children are able to learn mathematics and L2 at the same time, this could be a serious argument in favor of bilingual education. Of course, further research will still be needed on this subject, in order to understand this phenomenon in a wider range, including aspects such as IQ or socio-economic status.

Both quantitative and qualitative parts of this study helped to shed light on bilingual education and two-way immersion. First, learning in L2 as well as in an important school discipline such as mathematics appear to develop in a considerable way. Second, the teacher implication in the development of discipline competences of the pupils seems not to be hindered by linguistic considerations, which probably has an impact on the results in mathematics that have been shown in the quantitative part of this paper. Thirdly, the presence of code-switching can represent an advantage for the discipline as argued by Moore (2006). Thus we recommend presenting aspects such as code-switching, balance between language and contents or class interactions in teacher training as they can play a major role in the success of bilingual programs.

In conclusion, the use of mixed methods for this study has been useful in order to measure the competences of children of a two-way immersion program on the one hand and detecting the complex context of knowledge production and code-switching in the class on the other hand. Further research implying mixed methodologies on classroom interaction or teaching school subject in L2 and code-switching appear important for a better understanding of the complex phenomena regarding bilingual education.

\section{References}

Berthoud, A.-C. \& Gajo, L. (2005). Traitement des arguments et de leur mise en texte dans le processus de rédaction conversationnelle: continuité entre objets linguistiques et non linguistiques. In Bouchard, R. \& Mondada, L. (éds), Les processus de la rédaction collaborative (pp. 201-225). Paris: L'Harmattan.

Calvé, P. (1991). Vingt-cinq and d'immersion au Canada: 1965-1990. ELA, 82, 7-23.

Cathomas, R., \& Carigiet, W. (2008). Le plurilinguisme, une chance unique. Fribourg: Office cantonal du matériel scolaire.

Council of Europe (2001). Common European Framework of Reference for Languages: learning, teaching, assessment. Berlin: Langenscheidt.

Creswell, J. W. (1999). Mixed method research: Introduction and application. In T. Cijek (Ed.), Handbook of educational policy (pp. 455-472). San Diego, CA: Academic Press.

Gajo, L. (2001). Immersion, bilinguisme et interaction en classe. Paris: Editions Didier.

Humboldt-Universität Berlin. (2013). Institut zur Qualitätsentwicklung im Bildungswesen. Aufgabenpool VERA: https://www.iqb.hu-berlin.de/vera (01.12.2019).

Lenz, P., \& Studer, T. (2014). Lingualevel. Instrumente zur Evaluation von Fremdsprachenkompetenzen 5. Bis 9. Schuljahr. Burgforf: Schulverlag Plus.

Lyster, R. (1990). The role of analytic language teaching in French immersion programs. The Canadian Modern Language Review, 47, 159-176.

Moore, D. (2006). Plurilinguisme et école. Paris: Editions Didier.

Penfield, W. (1965). Conditioning the uncommitted cortex for Language learning. Brain, 88, 787-798.

Ronjat, J. (1913). Le développement du langage observé chez un enfant bilingue. Paris: Librairie Ancienne H. Champion.

Roulet, E. (1991). Vers une approche modulaire de l'analyse de discours. Cahier de linguistiques française, $12,53-81$ 